\title{
ANALISIS KEPUASAN MASYARAKAT TERHADAP PELAYANAN PUBLIK BERDASARKAN INDEKS KEPUASAN MASYARAKAT DI KANTOR KECAMATAN BELITANG KABUPATEN OKU TIMUR
}

\author{
Suandi \\ Staf Dosen Fakultas Ilmu Administrasi Universitas Sjakhyakirti \\ Email : suandiwidjaya23@gmail.com
}

\begin{abstract}
ABSTRAK
Penelitian ini bertujuan untuk mengetahui pelayanan Kantor Kecamatan Belitang Kabupaten OKU Timur yang diukur menggunakan Indeks Kepuasan Masyarakat. Penelitian ini merupakan jenis penelitian deskriptif dengan menggunakan analisis Indeks Kepuasan Masyarakat. Penelitian dilakukan di Kantor Kecamatan Belitang Kabupaten OKU Timur pada bulan Oktober 2018. Teknik sampling yang digunakan adalah non-probability sampling dengan jenis accidental sampling. Teknik pengumpulan data dilakukan dengan teknik observasi, dokumentasi dan angket. Uji validitas menggunakan rumus Product Moment Pearson dan uji reliabilitas menggunakan numus Cronbach"s Alpha. Dari hasil penelitian terlihat bahwa Indeks Kepuasan Masyarakat (IKM) untuk pelayanan Kantor Kecamatan Belitang adalah 2,88 dengan angka konversi sebesar 71,95. Maka kinerja pelayanan publik berada dalam kategori mutu pelayanan baik. Hasil daripengukuranterhadap 14indikator Indeks KepuasanMasyarakatsebagai berikut:

(a) prosedur pelayanan nilai IKM sebesar 75,08 dengan kategori baik, (b)Persyaratan pelayanan nilai IKM sebesar 71,83 dengan kategori Baik, (c) Kejelasan petugas pelayanan nilai IKM sebesar 69,33 dengan kategori Baik, (d) Kedisiplinan petugas pelayanan nilai IKM sebesar 73,33 dengan kategori Baik, (e) Tanggungjawab petugas nilai IKM sebesar 74,17 dengan kategori Baik,(f) kemampuanpetugas pelayanan dengan nilai IKM sebesar 66,83 dengan kategori baik, (g) Kecepatan pelayanan nilai IKM sebesar 72,17 dengankategori Baik,(h)Keadilan mendapatkanpelayanannilaiIKMsebesar 74,67dengankategori Baik,

(i) kesopanan dan keramahan petugas nilai IKM sebesar 75,17 dengan kategori baik, (j) Kewajaran biaya pelayanan nilai IKM sebesar 73,83 dengan kategori Baik, (k) Kepastian biaya pelayanan nilai IKM sebesar 68,50dengankategori Baik, (l) Kepastianjadwal pelayanannilai IKMsebesar 74,33dengankategori Baik,

(m) Kenyamanan lingkungan nilai IKM sebesar 74,67 dengan kategori Baik, dan(n) Keamanan pelayanan nilai IKMsebesar69,42dengankategoriBaik.
\end{abstract}

Kata Kunci : Pelayanan Publik, Indeks Kepuasan Masyarakat.

\section{A. PENDAHULUAN}

Pada dasarnya setiap manusiamembutuhkan pelayanan, bahkan pelayanan menjadi sesuatu yangtidakbisa dipisahkan danditinggalkan dalam kehidupan bermasyarakat. Setiap saat masyarakat selalu menuntut pelayanan yang berkualitas dari aparaturpemerintah yang memberikan pelayanan. Aktivitas pelayanan sangat berpengaruh terhadap pencapaian mutu dan kelancaran kegiatan dalam bermasyarakat. Pelayanan yang diberikan tidak hanya sekadar memberikan bantuan terhadap kebutuhan pelanggan, tetapi juga memberikan pelayanan yang baik kepada pelanggan. Menerima pelayanan yang memuaskan dari aparaturpemerintahmerupakan hak yang dimiliki setiapmasyarakat.
Masyarakat membutuhkan pelayanan untuk memenuhi berbagai macam kebutuhannya. Pelayanan publik yang sering dibutuhkan dalam bentuk barang publik maupun jasa publik. Dengan pelayanan yang diterima tersebut diharapkan masyarakat akan berpartisipasi aktif mendukung tugas-tugas aparatur pemerintah, sehingga terjadi keseimbangan antara hak dan kewajiban sebagai warga negara.

Pelayanan terhadap masyarakat merupakan salah satu tugas yang harus dilaksanakan oleh pemerintah daerah maupun pemerintah pusat. Pemerintah mempunyai peranan penting untuk menyediakan pelayanan publik sesuai yang telah diamanatkan dalam Undang-Undang. Menurut Undang-Undang Nomor 25 
Tahun 2009 tentang Pelayanan publik pasal 1, pelayanan publik adalah rangkaian kegiatan dalam rangka pemenuhan kebutuhan pelayanan sesuai dengan peraturan perundang-undangan bagi setiap warga negara dan penduduk atas barang,jasa dan/atau pelayanan administratif yang disediakanolehpenyelenggarapelayananpublik.

Kualitas pelayanan merupakan suatu kondisi dimana tercipta hubungan yang dinamis antara pengguna maupun pemberi layanan, baik jasa, manusia. Apabila layanan yang diberikan sudah sesuai dengan yang diharapkan oleh pengguna layanan, maka dapat dikatakan pelayanan tersebut merupakan pelayanan yang berkualitas. Sebaliknya jika layanan yang diberikan tidak sesuai dengan harapan pengguna layanan, maka dapat dikatakan pelayanan tersebut tidak berkualitas. Baik buruknyakualitas layanan bukan berdasarkan sudut pandang ataupersepsi penyedia jasa dan/ atau layanan melainkan berdasarkan pada persepsi konsumen dan aturan atau ketentuantentangkualitaspelayanan.

Masyarakat pada umumnya mengharapkan pelayanan yang baik. Pelayanan yang buruk akan menimbulkan citra negatif bagi pemerintah tersebut. Pelayanan yang diberikan oleh birokasi pemerintah di Indonesia adalah hal yang bersifat umum dan telah banyak terjadi, yaitu lambatdan bertele-telenya penyelesaian administrasi suatu urusan. Bila ingin mendapatkan pelayanan yang optimal, masyarakat harus melakukan balas jasa (feedback) dengan membayar dalam jumlah tertentu, maka hal ini termasuk kategori penyuapan dan biasanya digariskan termasuk ke dalam perbuatan korupsi, kolusi dan nepotisme $(\mathrm{KKN})$. Ini artinya pelayanan yang diberikan belum memuaskan. Hal ini mengakibatkan masyarakatenggan mengurussegala sesuatu yang berhubungan dengan birokrasi pemerintah secara langsung.

Kecamatan merupakan ujung tombak pelayanan terhadap masyarakat dan juga disebut sebagai basis pelayanan publik. Hal ini tidaklah berlebihan jika dilihat dalam kegiatan sehariharinya, masyarakat setiap harinya melakukan pengurusan baik perizinan maupun permohonan mendapatkan surat keterangan. Di dalam pemerintah daerah terdapat level pemerintahan terbawah yaitu organisasi kecamatan yang berada $\mathrm{d}$ bawah dan bertanggung jawab kepala camat. Salah satu kecamatan yang aktivitasnya memberikan pelayanan publik kepada masyarakat adalah Kantor Kecamatan Belitang, Kabupaten OKU Timur. Layanan yang diberikan contohnya pembuatan Kartu Keluarga, Kartu Tanda Penduduk, Pengurusan Izin Mendirikan Bangunan (IMB), dan fasilitas pelayanan pemerintahan lain bagi masyarakat ataupun bagi pemerintahditingkatdesa.

Berdasarkan pengamatan awal yang telah dilakukan di Kantor Kecamatan Belitang, terdapat beberapa permasalahan yang dijumpai pada bagian pelayanan. Fasilitas pelayanan merupakan salah satu aspek yang memengaruhi kualitas pelayanan yang diberikan. Oleh karena itu, pemenuhan fasilitas pelayanan bagi pelanggan atau masyarakat merupakan salah satu hal yang perlu diperhatikan. Fasilitas pelayanan di Kantor Kecamatan Belitang dianggap masih kurang memadai, seperti kurang luasnya ruang tunggu, dan tempat duduk pada ruang tunggu yang masih kurang. Hal ini tentu saja dapat menghambat kelancaran kegiatan pelayanan. Tujuan utama pelayanan publik adalah tercapainya kepuasan masyarakat. Kepuasan masyarakat akan terwujud apabila pelayanan yang diberikan sesuai dengan standarpelayanan yang telah ditetapkan atau lebih baikdaristandaryangditetapkan.

Kegiatan pelayanan yang diberikan di Kantor Kecamatan Belitang akan dinilai melalui tingkat kepuasan masyarakat. Masyarakat memberikan penilaian untuk menentukanukuran kinerja pelayanan publik. Kegiatan yang dilakukan untuk mengetahui pelayanan publik adalah mengukur tingkat kepuasan masyarakat. Salah satu metode yang digunakan untuk mengetahui kualitas pelayanan suatu organisasi publik adalah dengan menggunakan Indeks Kepuasan Masyarakat (IKM). Ketentuan mengenai Indeks Kepuasan Masyarakat (IKM) tertuang dalam Keputusan Menteri Pendayagunaan Aparatur Negara Nomor KEP/25/M.PAN/2/2004 tanggal 24 Februari 2004 tentang Pedoman Umum Penyusunan Indeks Kepuasan Masyarakat Unit Pelayanan InstansiPemerintah.

Analisis Indeks Kepuasan Masyarakat (IKM) harus selalu dilakukan secara berkala. Artinya pada setiap periode waktu tertentu harus dilakukan penelitian atau perhitungan dan analisis terhadap kepuasan masyarakat akan pelayanan yang telah diberikan. Namun, Kantor Kecamatan Belitang sampai saat ini belum dilakukan secara berkala. Hal ini menjadi menarik untuk dikaji 
dengan maksud untuk mengetahui mengenai Indeks Kepuasan Masyarakat terhadappelayanan di Kantor Kecamatan Belitang. Berdasarkan penjabaran di atas, maka akan dilakukan penelitian dengan judul Analisis Kepuasan Masyarakat terhadap pelayanan Publik Berdasarkan Indeks Kepuasan Masyarakat di Kantor Kecamatan Belitang Kabupaten OKU Timur.

Berdasarkan identifikasi masalah diatas, perlu dibatasi cakupan permasalahan yang lebih sempit. Permasalahan dalam penelitian ini difokuskan pada kualitas pelayanan Kantor Kecamatan Belitang diukur berdasarkan Indeks Kepuasan Masyarakatbelumdiketahui.

Berdasarkan masalah yang telah dipaparkan, masalah dalam penelitian ini adalah sebagai berikut: "Bagaimana pelayanan Kantor Kecamatan Belitang Kabupaten OKU Timur diukur berdasarkan kepuasan masyarakat menggunakan Indeks Kepuasan Masyarakat?'

Sesuai dengan rumusan masalah di atas, tujuan yang ingin dicapai oleh peneliti dalam melakukan penelitian ini adalah mengetahui pelayanan Kantor Kecamatan Belitang Kabupaten OKU Timur diukur berdasarkan kepuasan masyarakat menggunakan Indeks Kepuasan Masyarakat.

\section{B. KAJIAN PUSTAKA \\ A. PengertianPelayananPublik \\ 1. PelayananPublik}

a. Pengertian Pelayanan

Menurut Hardiyansah (2011: 11) mendefinisikan bahwa " pelayanan dapat diartikan sebagai aktivitas yang diberikan untuk membantu, menyiapkan, dan mengurus baik itu berupa barang atau jasa dari satu pihak ke pihak lain". Pelayanan pada hakikatnya adalah serangkaian kegiatan, karena itu prosespelayanan berlangsung secara rutin dan berkesinambungan, meliputi selunuh kehidupan organisasi dalam masyarakat. Proses yang dimaksudkan dilakukan sehubungan dengan saling memenuhi kebutuhan antarapenerimadan pemberipelayanan.

Dari definisi tersebut dapat disimpulkan bahwa pelayanan adalah aktivitas atau kegiatan atau usaha yang dilakukan seseorang atau sekelompok orang melalui hubungan interaksi antara satu pihak ke pihak lain yang menggunakan peralatan berupa organisasi atau lembaga perusahaan untuk kepuasan penerima/pelanggan/konsumen.

\section{b. Pengertian Publik}

Istilah publik berasal dari bahasa inggris public yang berarti umum, masyarakat, dan negara. Kata public sebenarnya sudah diterima menjadi bahasa Indonesia baku menjadi publik yang berarti umum, orang banyak, dan ramai. Inu dan kawan-kawan (1999: 18) mendefinisikan publik adalah sejumlah manusia yang memiliki kebersamaan berfikir, perasaan, harapan, sikap atau tindakan yang benar dan baik berdasarkan nilai-nilai norma yang merasa memiliki. Menunut Gruth dan Marsh dalam Estawara (2010), publik adalah setiap kelompok orang yang memiliki minat atau nilai-nilai bersama dalam situasi tertentu, terutama kepentingan atau nilai-nilai mereka mungkin bertindak atas kesediaan. Dari beberapa definisi diatas maka dapat disimpulkan publik adalah sekelompok orang/individu yang memiliki kepentingan dan minat yang sama akan sesuatuhal.

\section{c. Pelayanan Publik}

Berdasarkan Undang Undang No. 25

Tahun 2009 tentang PelayananPublik yaitu: Pelayanan publik adalah segala bentuk kegiatan dalamrangkapengaturan, pembinaan, bimbingan, penyediaan fasilitas, jasa dan lainnya yang dilaksanakan oleh aparatur pemerintah sebagai upaya pemenuhan kebutuhan kepada masyarakat sesuai ketentuan perundang-undangan yang berlaku. Pelayanan publik tidak terlepas dari masalah kepentingan umum. Pelayanan publik dibutuhkan masyarakat guna menunjang berbagai kebutuhannya. Pelayanan publik menurut Sinambela (Harbani Pasolong, 2010: 199) adalah setiap kegiatan yang dilakukan oleh pemerintah terhadap sejumlah manusia yang memiliki setiap kegiatan dan menawarkan kepuasan meskipun hasilnya tidak terikat pada suatu produk secara fisik.

\section{Jenis-JenisPelayananPublik}

Berdasarkan keputusan MENPAN No. 63/ KEP/ M. PAN/ 7/ 2003 tentang Pedoman Umum Penyelenggaraan Pelayanan Publik mengelompokkan tiga jenis pelayanan dari instansi pemerintah serta BUMN/BUMD, yaitu sebagai berikut:

\section{PelayananAdministratif}


2 PelayananBarang

3. PelayananJasa

\section{KarakteristikPelayanan}

Zeithaml, Berry dan Parasuraman

(Fandy Tjiptono dan Anastasia Diana, 2003: 27) mengidentifikasikan lima karakteristik yang digunakan oleh para pelanggan dalam mengevaluasi kualitas jasa, yaitu:

1. Buktilangsung(tangible)

2 Kehandalan(reliability)

3. Dayatanggap(responsiveness)

4. Jaminan(assurance)

5. Empati

\section{Faktor-faktor yang Mempengaruhi} Pelayanan

Berikut beberapa faktor yang mempengaruhipelayanan, sebagai berikut:

1. Sumberdayamanusia

2 Kesadaran

3. Aturanorganisasi

4. Keterampilandankemampuan

5. Saranapelayanan

6 Pengalamanpelanggan.

\section{PengertianKualitasPelayanan}

Lovelock dalam Fandy Tjiptono (2005: 59), menyatakan bahwa kualitas pelayanan adalah suatu tingkat keunggulan yang diharapkan dan pengendalian atas tingkat keunggulan tersebut untuk memenuhi harapan pelanggan. Kualitas pelayanan adalahsuatu kondisi yang berhubungan dengan seberapa jauh pihak penyedia jasa dapat memberikan pelayanan yang sesuai dengan harapan pelanggannya. Berdasarkan kaitannya dengan kantor kecamatan, pihak kantor kecamatan sebagai penyedia jasa pelayanan diharapkan dapat memberikan pelayanan yang menyenangkandannyaman bagimasyarakat.

\section{ManfaatKualitasPelayanan}

Fandy Tjiptono dan Gregorius Chandra (2005: 115) menyebutkan bahwa terdapat beberapa manfaat yang dapat diperoleh sebuah perusahaan dengan adanya kualitas pelayanan, yaitu:

1. Kualitas berhubungan erat dengankepuasan pelanggan.
2. Perusahaan dapat meningkatkan pangsa pasamya melalui pemenuhan kualitas yang bersifat customer-driven.

3. Kualitasdapatmengurangibiaya.

\section{Dimensi Kualitas Pelayanan}

Parasuraman, et al., (Fandy Tjiptono, 2005: 690) mengidentifikasi sepuluh dimensi kualitas, yaitu:

1. Reliability

2. Responsiveness

3. Competence

4. Access

5. Courtesy

6. Communication

7. Credibility

8. Security

9. Understanding/Knowingthe Customer

10. Tangibles

\section{B PengertianKepuasanPelanggan \\ 1. KepuasanPelanggan}

Menurut Nasution M. N. (2001: 45), kepuasan pelanggan adalah suatu keadaan di mana kebutuhan, keinginan, dan harapan pelanggan dapat terpenuhi melalui produk yang dikonsumsi. Gerson dalam Arief (2007:167) menyatakan bahwa kepuasan pelanggan merupakan harapan yang telah terpenuhi atau terlampaui. Dari pendapat para pakar tersebut dapat disimpulkan kepuasan pelanggan adalah tingkat perasaan konsumen setelah membandingkan kesesuaian atau ketidaksesuaian antara harapan (expectation) pelanggan dengan persepsi/pelayanan yang diterima (kenyataan yang dialami).

\section{Tingkat KepuasanMasyarakat}

Kepuasan masyarakat terhadap organisasi publik sangatpenting karena berhubungan dengan kepercayaan masyarakat. Harbani Pasolong (2010: 221-222), menyatakan bahwa semakin baik kepemerintahandan kualitas pelayanan yang diberikan, maka akan semakin tinggikepercayaan masyarakat (high trust). Kepercayaan masyarakatakan semakin tinggi apabila masyarakat mendapatkan pelayananyang baik dan merasa terpuaskan akan pelayanan tersebut. 
Setiap penyelenggara pelayanan perlu mengukur kepuasan pelanggan guna melihat umpan balik maupun masukan yang dapat diambil oleh penyelenggara untuk keperluan pengembangan dan implementasi strategi peningkatan kepuasan pelanggan. Menurut KEPMENPAN Nomor 63 tahun 2003 tentang Pedoman Umum Penyelenggaraan Pelayanan Publik, ukuran keberhasilan penyelenggaraan pelayanan ditentukan oleh tingkat kepuasan penerima pelayanan. Kepuasan pelayanan dicapai apabila penerima pelayanan memperoleh pelayanan sesuai dengan yang dibutuhkan dan diharapkan. Oleh sebab itu, setiap penyelenggara pelayanan secara berkala melakukan survei Indeks Kepuasan Masyarakat. Kepuasan pelanggan dapat diukur menggunakan berbagai metode pengukuran. Kotler (Fandy Tjiptono, 2003: 148), secara sederhana mengemukakan empat metode yang dapat mengukur kepuasan pelanggan, yaitu sebagaiberikut:

1. SistemKeluhandanSaran

2 Survai KepuasanPelanggan

3. GhostShopping

4. Lost CustomerAnalysis

\section{Indeks KepuasanMasyarakat}

1. PengertianIndeks KepuasanMasyarakat Indeks Kepuasan Masyarakat (IKM) menurut KEPMENPAN NO KEP/25/M.PAN/2/2004 adalah data dan informasi tentang tingkat kepuasan masyarakat yang diperoleh dari hasil pengukuran secara kuantitatif dan kualitatif atas pendapatmasyarakat dalam memperoleh pelayanan dari aparatur penyelenggara pelayanan publik dengan membandingkan antara harapan dan kebutuhannya.

Tujuan pengukuran Indeks Kepuasan Masyarakat(IKM) menurut KEPMENPANNO KEP/25/M.PAN/2/2004 adalah untuk mengetahui perkembangan kinerja unit pelayanan di lingkungan instansi pemerintah yang dilaksanakan oleh instansi yang bersangkutan secara periodik. Dan bagi unit pelayanan di instansi pemerintah, hasil pengukuran dapat digunakan sebagai bahan untuk menetapkan kebijakan dalam rangka meningkatkan kualitas pelayanan publik selanjutnya. Dan bagi masyarakat IKM dapat digunakan sebagai gambaran kinerja pelayanan unit yang bersangkutan.

\section{Unsur-Unsur Indeks Kepuasan Masyarakat}

Sebagaimana yang tertuang dalam keputusan Menteri Pendayagunaan Aparatur Negara Nomor : Kep/25/M.PAN/2/2004 tentang pedoman umum penyusunan indeks kepuasan pelayanan masyarakat unit pelayanan instansi pemerintah, ada 14 unsur yang relevan, valid, dan reliabel sebagai unsur minimal yang harus ada untukdasarpengukurantingkatkepuasanyakni:

1. ProsedurPelayanan

2 PersyaratanPelayanan

3. Kejelasan petugaspelayanan

4. Kedisiplinanpetugaspelayanan.

5. Tanggungjawabpetugaspelayanan

6. Kemampuanpetugaspelayanan

7. Kecepatanpelayanan

8. Keadilanmendapatkanpelayanan.

9. Kesopanandankeramahan petugas

10. Kewajaranbiayapelayanan

11. Kepastianbiayapelayanan

12 Kepastianjadwalpelayanan

13. Kenyamananlingkungan

14. KeamananPelayanan.

\section{Langkah-Langkah Penyusunan Indeks KepuasanMasyarakat}

1) Persiapan,6harikerja;

2) Pelaksanaanpengumpulandata,6 harikerja;

3) Pengolahandataindeks, 6hari kerja;

4) Penyusunandanpelaporanhasil,6harikerja.

\section{PengolahanData}

Penghitungan Indeks Kepuasan Masyarakat terhadap 14 unsur pelayanan yang dikaji, setiap unsur pelayanan memiliki penimbang yang sama dengan rumus sebagai berikut:

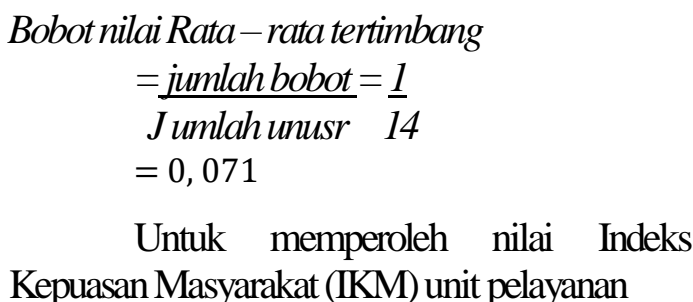


digunakan pendekatan nilai rata-rata tertimbang dengan rumus sebagai berikut:

$$
\text { Total dari nilai persepsi per Unsur }
$$

$I K M=$ Total unsur yang berisi

$x$ Nilai Penimbang

Untuk memudahkan interpretasi terhadap penilaian IKM yaitu antara 25 - 100 makahasil penilaian tersebut di atas dikonversikan dengan nilai dasar 25 , dengan rumus sebagai berikut :

\section{IKM Unit Pelayanan $\times 25$}

Berikut ini nilai persepsi dan interval IKM yang digunakan dalam penilaian 14 unsur IKM yang ditunjukkan pada tabel 1. sebagai berikut:

Tabel 1. Nilai Persepsi, Interval IKM, Interval Konversi IKM, Mutu Pelayanan dan Kinerja Unit Pelayanan

\begin{tabular}{|c|c|c|c|c|}
\hline $\begin{array}{c}\text { Nilai } \\
\text { Persepsi }\end{array}$ & $\begin{array}{c}\text { Nilai Interval } \\
\text { IKM }\end{array}$ & $\begin{array}{c}\text { Nilai Interval } \\
\text { Konversi IKM }\end{array}$ & $\begin{array}{c}\text { Mutu } \\
\text { Pelayanan }\end{array}$ & Kinerja Unit Pelayanan \\
\hline 1 & $1,00-1,75$ & $25-43,75$ & D & Tidak baik \\
\hline 2 & $1,76-2,50$ & $43,76-62,50$ & C & Kurang baik \\
\hline 3 & $2,51-3,25$ & $62,51-81,25$ & B & Baik \\
\hline 4 & $3,26-4,00$ & $81,26-100,00$ & A & Sangat baik \\
\hline
\end{tabular}

Sumber : KEPMEN PAN Nomor 25 Tahun 2004

\section{METODE PENELITIAN}

Desain penelitian ini merupakan penelitian deskriptif dengan pendekatan kuantitatif.Penelitian ini dilaksanakan di Kecamatan Belitang Kabupaten OKU Timur. Adapun pelaksanaan penelitian pada 06 Oktober s/d 06 November 2018.

Populasi dalam penelitian ini adalah seluruh masyarakat yang menjadi pelanggan di Kantor Kecamatan Belitang. Teknik sampling yang digunakan dalam penelitianini adalah teknik non-probability sampling dengan jenis accidental sampling. Sesuai dengan KEPMENPANNomor 25 Tahun 2004 sampel penelitian ditetapkan sejumlah 150 responden sesuai dengan jumlah minimal responden dalam penyusunan indeks kepuasan masyarakat yang dipilih secara tidak sengaja, dengan dasar (( jumlah unsur +1$)$

$$
\text { ( ) ). }
$$

Untuk memperoleh data yang diperlukan dalam penelitian ini peneliti menggunakan beberapa teknik pengumpulan data sebagaiberikut:
1. Observasi

2. Metodedokumentasi

3. Angket

Sebelum data yang diperoleh dianalisis terlebih dahulu dilakukan uji kualitas data yaitu uji validitas dan uji reliabilitas.Pengelolaan data penelitiandilakukandengancarasebagai berikut:

1. Editing

2. Tabulasi

3. AnalisisIKMdan Interpretasi

4. Penarikankesimpulan

\section{HASIL PENELITIAN DAN PEMBAHASAN}

\section{a. Hasil}

\section{Deskripsi Data Penelitian}

Berikut merupakan hasil yang diperoleh dalam penelitian ini yaitu terdiri dari :

A. Karakteristik Responden

a. Karakteristik responden berdasarkan umur

Tabel 2. Distribusi Masyarakat Pengguna Layanan Menurut Umur

\begin{tabular}{|c|c|c|}
\hline Umur & Frekuensi & Persentase (\%) \\
\hline $17-20$ & 21 & $14 \%$ \\
\hline $21-30$ & 39 & $26 \%$ \\
\hline $31-40$ & 34 & $22,67 \%$ \\
\hline $41-60$ & 56 & $37,33 \%$ \\
\hline Jumlah & $\mathbf{1 5 0}$ & $\mathbf{1 0 0}$ \\
\hline
\end{tabular}

Sumber: Data primer diolah 
b. Karakteristik responden berdasarkan Pendidikan

Tabel 3.Distribusi Masyarakat Pengguna Layanan Menurut Pendidikan

\begin{tabular}{|c|c|c|}
\hline Jenjang Pendidikan & Frekuensi & Persentase \\
\hline 'SD 4 & 6 & $4 \%$ \\
\hline SMP & 13 & $8,67 \%$ \\
\hline SMA/SMK & 105 & $70 \%$ \\
\hline Diploma III & 6 & $4 \%$ \\
\hline S 1 & 20 & $13,33 \%$ \\
\hline Jumlah & $\mathbf{1 5 0}$ & $\mathbf{1 0 0}$ \\
\hline
\end{tabular}

Sumber: Data primer diolah

c. Karakteristik responden berdasarkan Jenis Pekerjaan

Tabel 4. Distribusi Masyarakat Pengguna Layanan Menurut Jenis Pekerjaan

\begin{tabular}{|c|c|c|}
\hline Jenis Pekerjaan & Frekuensi & Persentase \\
\hline PNS/TNI/Polri & 34 & $22,67 \%$ \\
\hline Pegawai Swasta & 16 & $10,67 \%$ \\
\hline Wirausaha & 26 & $17,33 \%$ \\
\hline Petani / Buruh & 40 & $26,67 \%$ \\
\hline Pelajar/Mahasiswa & 9 & $6 \%$ \\
\hline Lainnya & 25 & $16,67 \%$ \\
\hline Jumlah & $\mathbf{1 5 0}$ & $\mathbf{1 0 0}$ \\
\hline
\end{tabular}

Sumber: Data primer diolah

B. Analisis Indeks Kepuasan Masyarakat (IKM)

Berikut merupakan data dan informasi tentang tingkat kepuasan masyarakat yang diperoleh dari hasil pengukuran secara kuantitatif dan kualitatif atas pendapat masyarakat dalam memperoleh pelayanan dari aparatur penyelenggara pelayanan publik dengan membandingkan antara harapan dan kebutuhannya. Kepuasan pelayanan dicapai apabila penerima pelayanan memperoleh pelayanan sesuai dengan yang dibutuhkan dan diharapkan. Oleh sebab itu, setiap penyelenggara pelayanan secara berkala melakukan survei Indeks Kepuasan Masyarakat.

Berikut merupakan data statistik analisis kepuasan masyarakat terhadap pelayanan public dikantorkecamatan belitang.

Tabel 5. Data Statistik Anailsis Kepuasan Masyarakat Terhadap Pelayanan Publik di Kantor Kecamatan Belitang

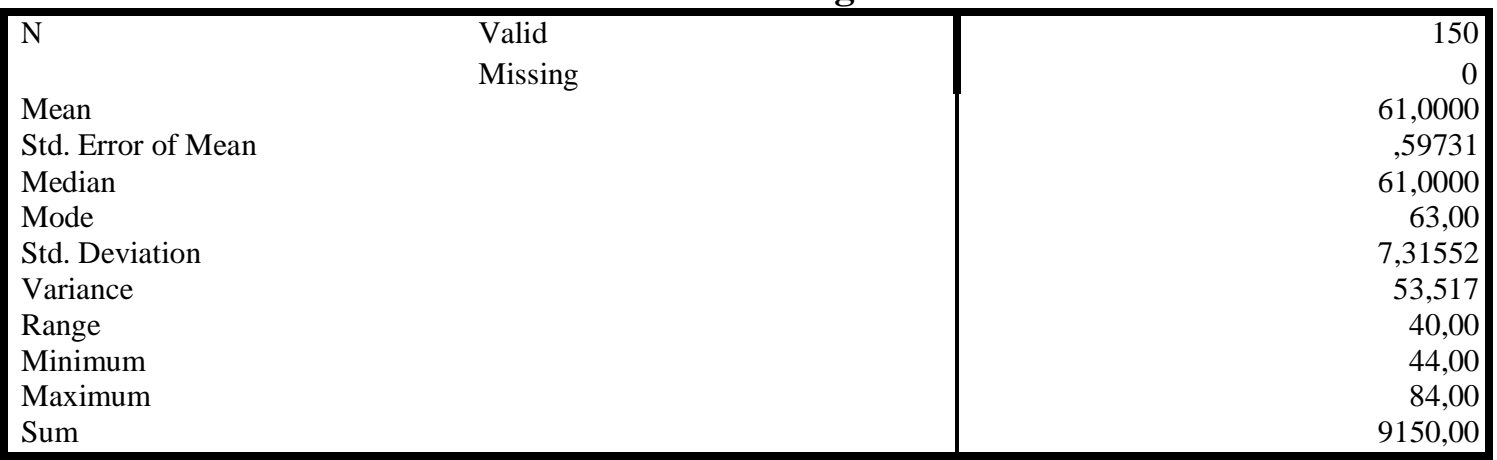

Sumber: Data Primer diolah

Berdasarkan pengukuran terhadap 14 unsur pelayanan (U), diperoleh perhitungan Indeks Kepuasan Masyarakat (IKM) kantor Kecamatan Belitang Kabupaten OKU Timur mengacu pada datapengolahan Indeks Kepuasan Masyarakat per-unsur pelayanan dapat dilihat pada Tabel6 dibawahini. 
Tabel 6. Data Pengolahan Indeks KepuasanMasyarakat per-Unsur Pelayanan

\begin{tabular}{|c|c|c|c|}
\hline Unsur & Jumlah & NRR & NRR Tertimbang \\
\hline U1 & 901 & 3,00 & 0,21 \\
\hline U2 & 862 & 2,87 & 0,20 \\
\hline U3 & 416 & 2,77 & 0,20 \\
\hline U4 & 440 & 2,93 & 0,21 \\
\hline U5 & 445 & 2,97 & 0,21 \\
\hline U6 & 401 & 2,67 & 0,19 \\
\hline U7 & 866 & 2,89 & 0,20 \\
\hline U8 & 448 & 2,99 & 0,21 \\
\hline U9 & 451 & 3,01 & 0,21 \\
\hline U10 & 886 & 2,95 & 0,21 \\
\hline U11 & 411 & 2,74 & 0,19 \\
\hline U12 & 446 & 2,97 & 0,21 \\
\hline U13 & 1344 & 2,99 & 0,21 \\
\hline U14 & 833 & 2,78 & 0,20 \\
\hline Total & 9150 & 44,00 & 2,88 \\
\hline
\end{tabular}

Sumber : Data Primer diolah

Nilai Konversi IKM $=2,88 \times 25=71,95$

Berdasarkan kategori mutu pelayanan pada Tabel 1, maka Kantor Kecamatan Belitang Kabupaten OKU Timur memperoleh hasil Konversi IKM sebesar 71,95 yang berarti berada dalam mutu pelayanan "B" dengan kategori "BAIK".
Apabila dilihat dari masing-masing unsur Indeks Kepuasan Masyarakat, yang mengacu pada kategorisasi mutu pelayanan pada tabel 1, nilai IKM dari setiap unsur pelayanan dapatdilihat padatabel 7 berikut.

Tabel 7. Hasil Indeks Kepuasan Masyarakat Per-Unsur Pelayanan

\begin{tabular}{|c|l|c|c|c|c|}
\hline No & \multicolumn{1}{|c|}{ Unsur Pelayanan } & $\begin{array}{l}\text { Nilai } \\
\text { IKM }\end{array}$ & $\begin{array}{l}\text { Nilai } \\
\text { Konversi }\end{array}$ & $\begin{array}{l}\text { Mutu } \\
\text { Pelayanan }\end{array}$ & Kinerja \\
\hline 1 & Prosedur pelayanan & 3,00 & 75,08 & B & Baik \\
\hline 2 & Persyaratan pelayanan & 2,87 & 71,83 & B & Baik \\
\hline 3 & Kejelasan petugas & 2,77 & 69,33 & B & Baik \\
\hline 4 & Kedisiplinan petugas & 2,93 & 73,33 & B & Baik \\
\hline 5 & Tanggung jawab petugas & 2,97 & 74,17 & B & Baik \\
\hline 6 & Kemampuan petugas & 2,67 & 66,83 & B & Baik \\
\hline 7 & Kecepatan pelayanan & 2,89 & 72,17 & B & Baik \\
\hline 8 & Keadilan mendapat pelayanan & 2,99 & 74,67 & B & Baik \\
\hline 9 & Kesopanan dan keramahan & 3,01 & 75,17 & B & Baik \\
\hline 10 & Ketugas & & & & Baik \\
\hline 11 & Kepastian biaya & 2,95 & 73,83 & B & Baik \\
\hline 12 & Kepastian jadwal & 2,97 & 74,33 & B & Baik \\
\hline 13 & Kenyamanan pelayanan & 2,99 & 74,67 & B & Baik \\
\hline 14 & Keamanan pelayanan & 2,78 & 69,42 & B & Baik \\
\hline
\end{tabular}

Sumber: Data primer diolah 
Pada tabel di atas terlihat bahwa untuk setiap unsur Indeks Kepuasan Masyarakat mendapat kategori Baik. Ini artinya mutu pelayanan di Kantor Kecamatan Belitang Kabupaten OKU Timurdinyatakan baik.

\section{b. Pembahasan}

Hasil penelitian menunjukkan bahwa pelayanan Kantor Kecamatan Belitang, Kabupaten OKU Timur berada pada kategori Baik. Hal ini ditunjukkan dengan nilai Indeks Kepuasan Masyarakat (IKM) dari 14 unsurIKM sebesar 2,88 dan dengan nilai konversi IKM sebesar 71,95. Ini artinya mutu pelayanan di Kantor Kecamatan Belitang Kabupaten OKU Timur dinyatakan baik. Namun ada beberapa masyarakat yang menggaanggap pelayanan di Kantor Kecamatan Belitang kurang baik atau belum baik, untuk ituperlu melakukan perbaikan dibeberapaunsuryangmasihdianggapkurang.

Indikator yang memiliki nilai IKM tertinggi adalah kesopanan dan keramahan petugas dengan nilai IKM sebesar 3,01 dengan nilai konversi IKM sebesar 75,17. Nilai IKM kesopanan dan keramahan petugas pelayanan Kantor Kecamatan Belitang perlu dipertahankan atau jika dimungkinkan untukditingkatkan.

Sedangkan indikator yang memiliki nilai IKM terendah adalah indikator kemampuan petugas mendapatkan nilai IKM sebesar 2,67 dan nilai konversi IKM sebesar 66,83.Indikator Kemampuan petugas pelayanan merupakan indikator IKM yang paling rendah dibandingkan dengan indikator lainnya dan berada pada tingkat pelayanan kurang baik. Berdasarkan uraian tersebut, kemampuan petugas pelayanan di Kantor Kecamatan Belitang perlu untuk ditingkatkan.

\section{KESIMPULAN}

Berdasarkan perhitungan Indeks Kepuasan Masyarakat yang mengacu pada Keputusan Menteri Pendayagunaan Aparatur Negara Nomor KEP/25/M.PAN/2/2004, maka diperoleh angka indeks sebesar 71,95 yang berada pada interval 62,51 - 81,25, sehingga kualitas pelayanan publik berada pada tingkat "B(Baik)". Hal ini menunjukkan bahwa kinerja pelayanan Kantor Kecamatan Belitang secara keseluruhan termasukdalamkategoribaik.

Berdasarkan 14 unsur pelayanan yang diteliti, kesopanan dan keramahan petugas merupakan unsur dengan nilai indeks tertinggi dengan nilai IKM sebesar 75,17 dan berada pada tingkat baik. Sedangkan unsur dengan nilai indeks terendah yaitu unsur kemampuan petugas pelayanan dengan nilai IKM sebesar 66,83 dan beradapadatingkatbaik.

\section{E. SARAN}

1. Pelayanan Kantor Kecamatan Belitang tergolong baik. Untuk kedepannya maka, pelayanan yang diberikan dipertahankan atau jika mungkin dapat terus ditingkatkan agarmenjadilebihbaiklagi.

2 Unsur kesopanan dan keramahan petugas dengan nilai IKM tertinggi perlu dipertahankan.

3. Kemampuan petugas pelayananmerupakan unsur dengan nilai IKM terendah dibandingkan dengan unsur lainnya, oleh karenaitu Kantor Kecamatan Belitangharus berupaya untuk meningkatkan kemampuan petugaspelayanan.

4. Kantor Kecamatan Belitang perlu untuk menambah jumlah petugas pelayanan agar prosespelayanansemakinbaikdancepat.

5. Kantor Kecamatan Belitang perlu memberikan informasi pelayanan yangjelas kepada setiap masyarakat. Contohnya menunjukkan papan informasi mengenai prosedur, persyaratan, biaya, dan waktu pelayanan pada setiap jenis pelayanan yang dapatdilihatlangsungolehmasyarakat.

6. Kantor Kecamatan Belitang perlu menambah petugas keamanan agar masyarakat merasa aman ketika berada di kantorKecamatanBelitang.

\section{DAFTAR PUSTAKA}

Estawara, Helpris. 2010. Stakeholder Relationship IN Intgrated Marketing Communication. JakartaUniversitasPancasila.

Hardiyansyah. 2011. Kualitas Pelayanan Publik Konsep, Dimensi, Indikator, danImplementasinya. Yogyakarta: Gava Media.

Kencana Syafiie, Inu. 1999. Ilmu Administrasi Publik. Jakarta: PT. Rineka Cipta. 
Keputusan Menteri Pendayagunaan Aparatur Negara Nomor 63/KEP/M.PAN//2003 tentang Pedoman Umum PenyelenggaraanPelayananPublik.

Keputusan Menteri Pendayagunaan Aparatur Negara Nomor: KEP/25/M.PAN/2004 tentang Pedoman Umum Penyusunan Indeks KepuasanMasyarakat.

Nasution, M. N. 2001. Manajemen Mutu Terpadu (Total Quality Management). Jakarta: GhaliaIndonesia.

Pasolong, Harbani. 2010. Kepemimpinan Birokrasi. Bandung: CV Alfabeta.

Tjiptono, Fandy dan Anastasia Diana. 2003. Total Quality Management. Yogyakarta: Andi Offset.

Tjiptono, Fandy dan Gregorius Chandra. 2005. Service, Quality \& Satisfaction. Yogyakarta: Andi Offset.

Undang-Undang Nomor 25 tahun 2009 tentang PelayananPublik 